\title{
Original Research \\ The Impact of the Changing Climate on Fire Activity in Muğla Region
}

\author{
Tuğrul Varol*, Mertol Ertuğrul \\ Faculty of Forestry, Bartin University, Turkey \\ Received: 6 May 2014 \\ Accepted: 8 July 2014
}

\begin{abstract}
It is a known fact that there is a relationship between forest fires and climate factors. Therefore, researchers have always been interested in revealing this relationship and its level in order to struggle with fires. Today, due to the changing climate in the world, this relationship is in a differentiation process. In many countries, researchers have started to study the relationship between fires and climate factors more often. The reason behind is the fact that, besides the change in climate, there is an obvious change in fire activity. The aim is not only to take the measures against fires, but also to estimate possible future forest fires. In order to reveal the relationship between climate change and forest fires, the effects of temperature, precipitation, relative humidity, wind, insolation, cloudiness, and other climatic factors on forest fires can be examined. In the current study, the Muğla Region has been chosen as the study area because of its high forest fire activity rate.

The relationship between the number of fires and the area burned and the relationship between these components and annual temperature, summer temperature, annual precipitation, and summer precipitation averages were analyzed. Moving from the results obtained from the relationship between positive and negative changes, this study examines the effect of changes in precipitation and temperatures on fire activity.
\end{abstract}

Keywords: climate change, forest fires, Muğla, precipitation, temperature

\section{Introduction}

The effect of climatic change is one of the numerous factors causing forest fires which are believed to have increased recently $[1,2]$. In this study, the Muğla region has the highest values in Turkey in terms of both number of fires and area burned, and is examined from the aspects of fire and climate parameters. Meteorological data obtained from 734 stations are used in order to identify the climatic characteristics of Turkey, while data obtained from 33 stations are used to identify the climatic characteristics of Muğla.

The changing trends in the number of fires and the area burned recently and the effect of climatic factors on this trend have been determined. The main aim of this study is not to make certain climate analysis, but to highlight the

*e-mail: tvarol@bartin.edu.tr overall climate changes in the study area within the scope of the fire information.

There are many scientific studies on forest fires in the Mediterranean. It is widely known that the Mediterranean climate and vegetation are fit for more significant fire hazards (Table 1).

As one of the countries where the Mediterranean climate and vegetation prevails, the temperatures in Turkey are rising and summers are turning out to be drier, and thus the forest fire hazard is increasing daily. In the graphics since 1850 (Fig. 1), it is seen that the world climate has been in a warming trend in the last century.

The most important factor for fire regimes is climate. Besides climate, the human-caused factors such as firefighting policy, forest management, changing landscape configuration, and expansion of exotic species also affects the forest regime [5]. Such human-caused wildland-urban 
Table 1. Forest fire hazard classification [3].

\begin{tabular}{|c|c|c|c|c|c|}
\hline $\begin{array}{l}\text { Observed forest fires } \\
\text { per } 100 \mathrm{~km}^{2}\end{array}$ & $\begin{array}{l}\text { Hazard } \\
\text { class }\end{array}$ & Biogeographic regions & $\begin{array}{l}\text { Hazard } \\
\text { class }\end{array}$ & $\begin{array}{l}\text { Resulting } \\
\text { sums }\end{array}$ & $\begin{array}{c}\text { Resulting forest fire } \\
\text { hazard classes }\end{array}$ \\
\hline No forest fires & 1 & Alpine and Arctic & 1 & $2-3$ & 1 Very low hazard \\
\hline 1 & 2 & Atlantic & 2 & $4-5$ & 2 Low hazard \\
\hline $2-5$ & 3 & Boreal & 3 & $6-7$ & 3 Medium hazard \\
\hline $6-10$ & 4 & Continental, Black Sea & 4 & $8-9$ & 4 High hazard \\
\hline$>10$ & 5 & Mediterranean & 5 & 10 & 5 Very high hazard \\
\hline
\end{tabular}

interfaces - factors that affect fire risk such as flammable material conditions and land use - could sometimes be preventive and sometimes an additive factor [6].

There are many studies on the relationship between climate and fire activity around the world, especially since the 1990s, with increasing recognition regarding the fact that climate change is increasing, along with the number of studies on the issue. While talking about the relationship between climate and fire activity, it is impossible not to talk about global climate change. In one study, in which many scientists from all around the world discussed the global climate, it was found that the temperatures in many large areas in South America, South Asia, Australia, and New Zealand increased significantly in 2009.

Among these countries, Australia had its second warmest year on record, India had its warmest year, Alaska had its second warmest July, and New Zealand had its warmest year in 155 years since they started taking records. Besides temperature, drought also has been seen in North America, the Caribbean, South America, and in large lands in Asia. In 2009 China had the worst drought of the last 50 years and with the decrease in monsoon rains in India, it had a very dry June. In addition, in the section for Turkey, it has been stated that the average temperature in Turkey in 2009 was $0.9^{\circ} \mathrm{C}$ higher than the average of 1971-2000 [7].

Many scientific studies have been carried out on revealing fire hazards using climate data. A study carried out about North America in 2001 stated that there would be an increase in fire intensity in the USA in all climate scenarios for the future, and that there would be a $25-50 \%$ increase in the land burned [8]. Another study carried out on Canada found that climate change could increase temperatures and change rainfall in Canada. In estimations for Ontario, it was projected that temperatures would increase in future fire seasons and that precipitation would be relatively stable or increase at a small rate [9].

Another study on Canada predicted that there will be an increase of $1-1.5^{\circ} \mathrm{C}$ in average summer temperatures in 2040 , and a $4-5^{\circ} \mathrm{C}$ increase for 2090 . According to the projections, these changes in temperature will be accompanied by small changes in regional rainfall. However, due to the increase in evaporation in forests, this change will not compensate for the potential fall in humidity, and fuel humidity will therefore decrease. A 24\% increase in fires arising from lightning in 2040 and $80 \%$ increase in 2090 are projected.
In addition, a $7 \%$ increase is expected with regards to human-induced fires in 2040, while a $26 \%$ increase is expected for the 2090. However, these can be considered as optimistic projections since the changing precipitation is not included here. When the whole is considered, a 15\% increase in fire activity is expected in Ontario in 2040 and a $50 \%$ increase is expected for 2100 . Due to change in fire activity and behavior, a $30.21 \%$ increase is expected in escaped fires by the end of 2040 and an $80 \%$ increase by the end of the $21^{\text {st }}$ century. According to estimations made as a result of these figures, it is projected that firefighting expenses will increase. Excluding other economic variables, this increase will be around 16\% in 2040 and around $54 \%$ for 2090 [10]. In a different study about Canada, Girardin [11] has found that the main risk factors among climate factors in terms of forest fires were the increasing summer temperatures and summer drought.

In a study on large fires in Alaska in North America, it has been stated that the most determinant factor influencing the large fires in this area was the frequency and time of rainfall, and that these factors were more important on large fires compared to monthly temperature and monthly rainfall. In addition, in the last decade, the increase in large fire season frequency coincided with the increase in temperatures in Alaska during the same period. And this indicates that the increase in temperatures in Alaska had a significant impact on large fires [12].

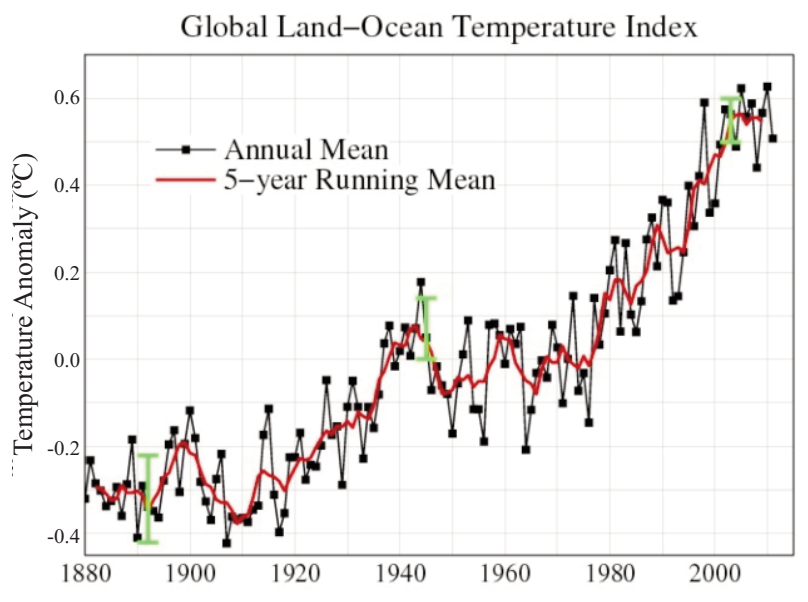

Fig. 1. Global land-ocean temperature index [4]. 
Going down to the Southwest USA, it is found that in addition to human-induced factors, other natural factors also effect the number of large forest fires. Among these natural factors are the amount of flammable materials, temperature, precipitation, wind, humidity, and lightning. Climate, on the other hand, especially affects temperature and precipitation, and burn and presence of flammable materials, and thus it has an effect on large fires. The presence of flammable materials particularly affects ecosystems containing dry and scattered plantation, and flammability affects the ecosystems containing humid and dense plantations. As a result, the distribution of vegetation and the fire regime types are strongly related to long-term averages of precipitation and temperature [13].

There are many studies examining the relationship between climate and fires in Europe. In one of these studies, Carvalho [14] found that there was a strong relationship between air conditions, the number of fires, and the area burned in fires. Due to the weather conditions projected for the future, it is estimated that there will be an increase in the number of fires and the area burned [14].

In another study of Zumbrunnen et al. [15], the effects of temperature, precipitation, drought, and dry foehn winds on the fires occurring in different places and times were compared. It was found that temperature and precipitation were the main determinants of fire regime in the Sub Alpine zone.

In such areas, foehn winds and even non-climatic factors have significant importance. The significance of certain factors has changed over time. While temperatures and precipitation were the main factors behind fires in the first half of the $20^{\text {th }}$ century, they lost their significance in the $2^{\text {nd }}$ half of the century. It was found in the study that although there was a significant increase in temperatures in Valais in the last century, there was no significant change in fire regime. However, in the second half of the $20^{\text {th }}$ century, temperatures were less effective on fire regime when compared to human-induced activities or the existence of biomasses in the forests. The total area burned annually increased significantly. And when the previous decades are analyzed, there seems to be a significant increase in the number of large fires. The study revealed that temperature and precipitation were the main actors in the frequency and the area burned in the $20^{\text {th }}$ century and that as of the mid$20^{\text {th }}$ century these factors had lost their importance. First of all, the increase in the amount of flammable materials arising from the use and management of forests should be considered. Then, developing firefighting techniques should be concentrated on and the increase in human-induced fires should also be taken into consideration [15].

Fire is a dominant ecological factor in Mediterranean ecosystems as well. In the study of Pausas [16] carried out in eastern Spain, the meteorological data collected from 350 stations between the years 1950-2000 and the fire data for the same area between the years 1874-1968 and 19682000 were utilized. The results of that study revealed a small decrease in summer rainfall and a significant increase in annual temperatures and summer temperatures. This increase is $0.35^{\circ} \mathrm{C}$ for every decade in $1950-2000$. The analysis of the fire records showed a significant increase in the number of fires and area burned throughout the last century.

However, although the number of fires increased in the last 30 years, the area burned in fires did not show a significantly increasing trend. This difference in trend is related

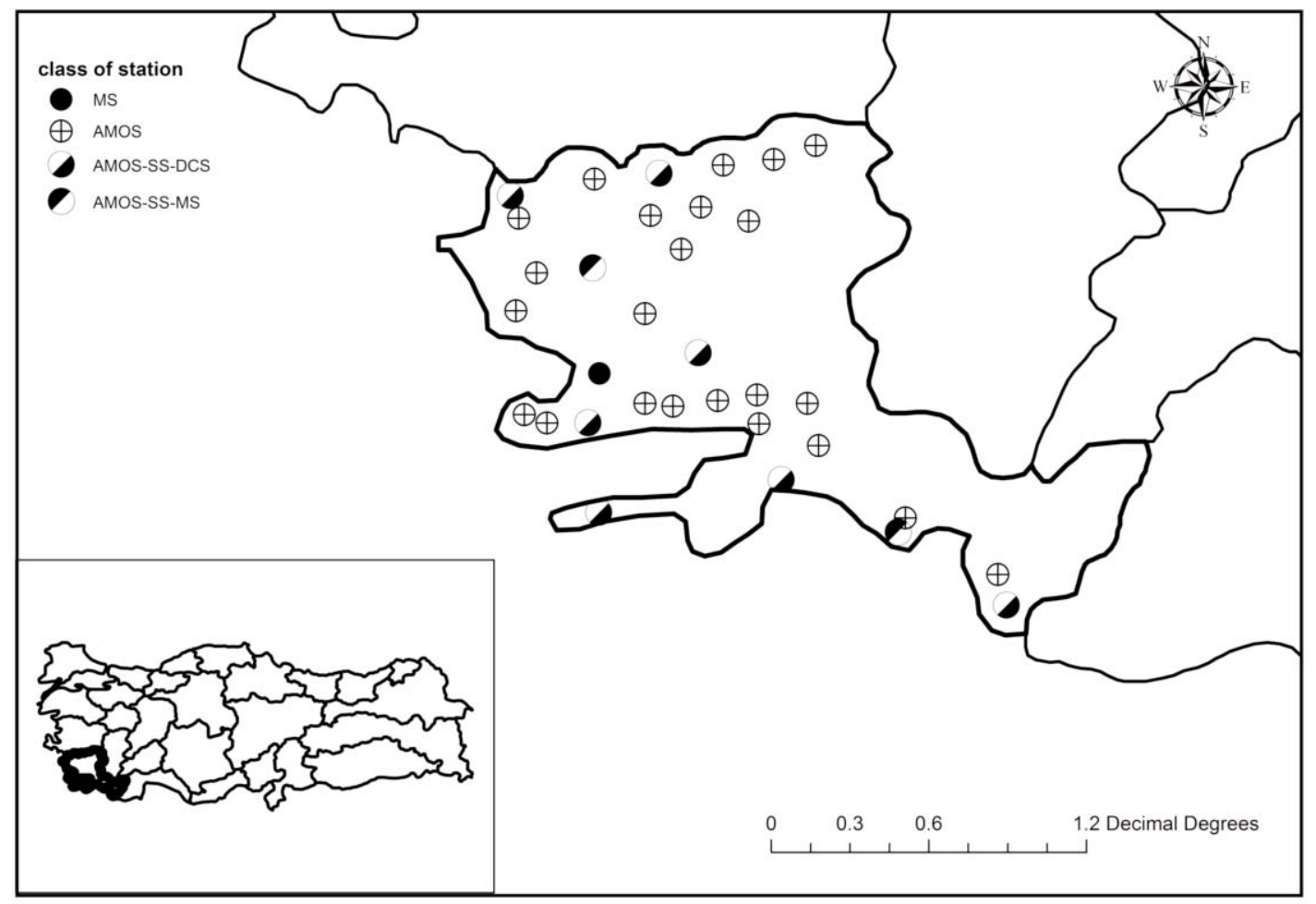

Fig. 2. The location of the study area and meteorological stations. 
to the amount of summer precipitation. Although it does not show a linear trend statistically, the result of several estimations showed that summer precipitation showed a decreasing trend over the last 50 years. This regional decrease in summer precipitation is $5.2 \mathrm{~mm}$ per decade. Summer precipitation, which determines the large part of the flammable material humidity in the fire season, is a significant criterion while estimating the area burned. The fires over the last 30 years caused the burning of larger areas in dry years when compared to other years having higher precipitation. The increase in natural areas, settlement area intersections, the abandoning of agricultural lands, and the increase of summer droughts and fire hazards seem inevitable for the future [16].

In a study by Pinol [17], on the other hand, it has been found in the analysis of meteorological records of Roquetes that there had been an increase in temperature and drought during the period 1910-94. The increase in drought here is not arising from the decrease in annual precipitation but from the increase in average temperatures and change in daily temperatures, and therefore causes high evapotranspiration. Since 1968 there has been an increase in fire activity in Spain due to dry and warming climate conditions. If actual trends continue, the high risk of fire in the Mediterranean region will also continue, and large forest fires will occur more frequently. Therefore, fire protection and firefighting policies should be reviewed by considering that conditions will worsen [17].

\section{Material and Methods}

Our study area is the Muğla region, which is one of the 27 General Directorates of Forestry in Turkey. Almost 56\% of the regional directorate $(2,048,603 \mathrm{ha})$ is forest area.

Muğla is located between $26^{\circ} 53^{\prime} \mathrm{E} 37^{\circ} 56^{\prime} \mathrm{N}$ and $29^{\circ} 47^{\prime}$ E $36^{\circ} 15^{\prime} \mathrm{N}$. The dominant climate is Mediterranean. The average annual precipitation is approximately $90 \mathrm{~mm}$, while the average temperature is $15^{\circ} \mathrm{C} .40 \%$ of the precipi- tation in the region falls in spring and autumn seasons, while $24 \%$ falls during the summer months.

Unlike Turkey, dry years are dry in the entire Muğla region, and humid years are humid too. This indicates that climatic variation over the years is homogenous for the region. Preliminary analysis showed that there is a $94.5 \%$ positive correlation among the 33 meteorological stations' data, and this data is found to explain $80.1 \%$ of the events at $95 \%$ confidence level.

A Similar study was carried out in eastern Spain by Pausas [16] in 2004, who examined the relationship of the forest fire activity in that region with meteorological data. In order to achieve accurate results, regression analysis, $\mathrm{F}$ test, and GAM function were utilized. According to the results of the study, no autocorrelation was found between the area burned in previous and following years. However, it was found in the consecutive 2-3 years after the year in which there were high number of fires, that there were also a high number of fires. This can be interpreted as a positive correlation at significant level. However, this positive trend was observed to decrease as of the $4^{\text {th }}$ year [16].

In our study that we carried out using a similar method in Turkey and in the Muğla Regional Directorate of Forestry, the data about the number of fires per year and the area burned during 1977-2011 was obtained from the annual fire reports prepared by the General Directorate of Forestry and annual assessment reports for the region.

Climate data of the study area were obtained as annual data from the General Directorate of Meteorology for the period of the study. Using the annual precipitation and average temperature values obtained from the stations, the annual average temperatures, annual precipitation, summer (June, July, and August) precipitation, and average summer temperatures were calculated.

Although the type of stations changed, temperature and precipitation data has been collected from all meteorological stations, and the distribution of 33 stations in Muğla is given in Fig. 2: where the dark-colored circles indicate MS
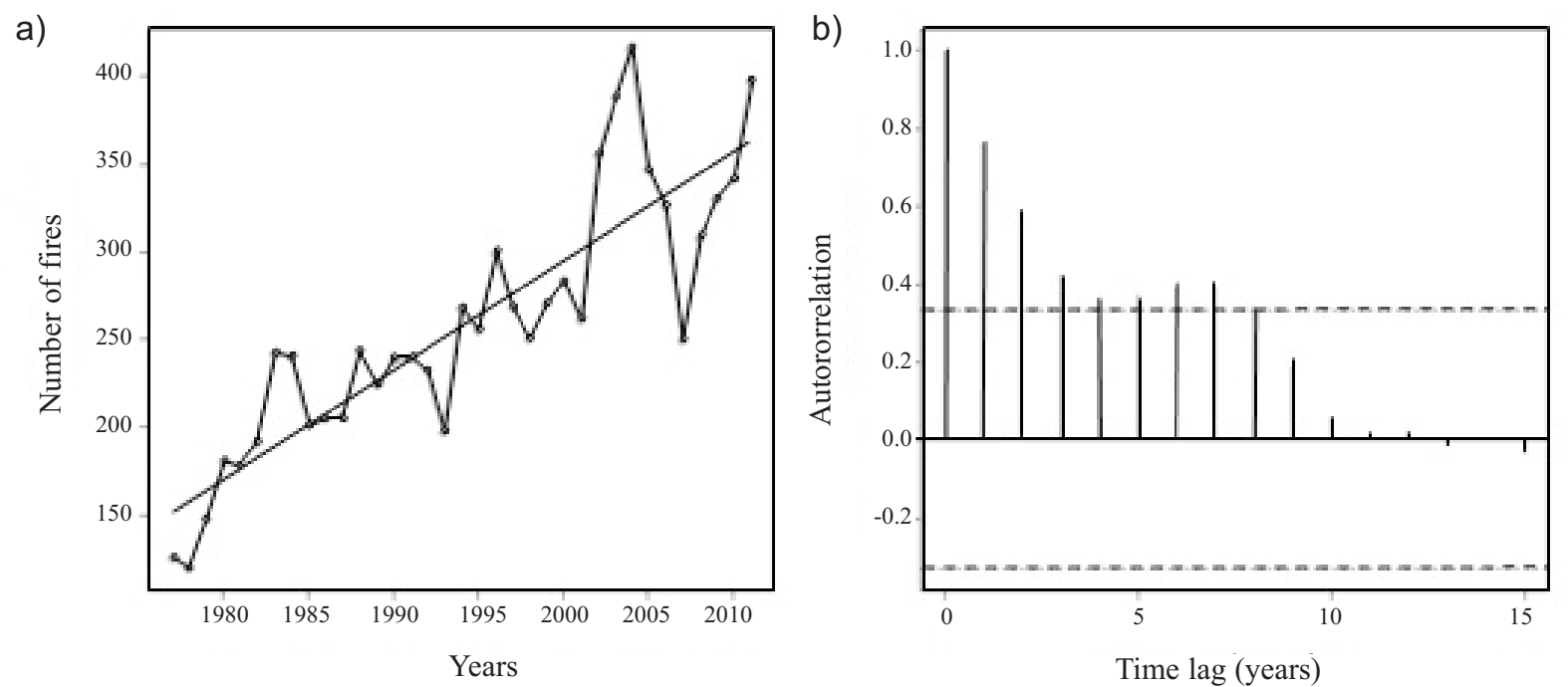

Fig. 3. The change in the annual number of fires in Muğla over the last 30 years.. 
(Metar Station), while empty circles indicate AMOS (Automatic Meteorological Observation Station), grey-colored circles indicate AMOS-SS-DCS (Automatic Meteorological Observation Station-Synoptic StationDaily Climate Station), and dotted circles indicate AMOSSS-MS (Automatic Meteorological Observation StationSynoptic Station-Metar Station) stations.

Besides the area burned and annual number of fires, when the climate data of the region are examined, it is obviously that the changes in climate are effective on fire information. In order to find out the significance level of the fire information and climate data, regression analysis and F-test were utilized. When no significant relationship was found among the data, it was tried to determine the inclination by utilizing smoothing GAM.

Autocorrelation analysis was carried out for the number of fires and annual area burned, and the cross-correlation analysis was carried out. Autocorrelation and cross-correlation were calculated using the times series package defined by Venables and Ripley [18].

\section{Results}

When the correlation between years and the number of fires in Turkey are analyzed, it is seen that there is a strong positive correlation ( 0.77 ), and that there is a negative correlation when the area burned is taken into account. Therefore, whereas there is an increase in the number of fires every other year, it is understood that the unit area burned in these fires decreases.

In the aforementioned studies, it is stated that the data on the number of fires and the area burned do not show a regular distribution.

The $p$ values of 0.0001096 for the number of fires and $2.915 \mathrm{e}-12$ for the area burned obtained from Shapiro test validate that these data do not show a normal distribution.

The high error ratio of 4640.494 and low $\mathrm{R}^{2}$ value of 0.5581 and high residual value for the number of fires and the years in Turkey show that the correlation between these two variables is weak. When the area burned is assessed by years, the high error rate of 259.017 , low $\mathrm{R}^{2}$ of 0.1975 , and high residual values show that there is no correlation between the area burned and the years.

In Muğla, which ranks first in Turkey in terms of number of forest fires and the area burned, different results have been obtained. As seen in Fig. 3a, there is an obvious increase in the number of fires in the last 30 years in the study area. An average of eight units increase has occurred in the number of annual fires. There is a significant autocorrelation in the number of fires in time lags shorter than nine years (Fig. 3b).

As a result of regression analysis, $F$ value for the change in the number of fires in time is found to be 103.6 and $\mathrm{p}<0.0001$. (The interrupted lines in the autocorrelation graphic in Fig. 3b show 95\% confidence interval.)

The annual area burned in the last 30 years has shown significant changes within years, and the variation reached maximum level in 1988 (almost 9,000 ha) and 2005 (almost 17,000 ha) (Fig. 4a). With regards to the amount of area burned, the temporal model does not show a significant autocorrelation (Fig. 4b). The temporal change in the area burned, including the GAM smoothing line, is shown in Fig. $4 \mathrm{~b}$ (the interrupted lines in the autocorrelation graphic in Fig. 4b indicate 95\% confidence interval).

When the change in average precipitation in Muğla in the last 30 years is examined, no clear inclination is seen (Fig. 5a). Although the precipitation data of summer months shows a decreasing trend, this decrease is not statistically significant due to the big differences in precipitation data in years $(p=0.06)$.

Besides, annual precipitation values do not show autocorrelation, and summer precipitation shows a negative autocorrelation in a two-year period.

Annual and summer temperatures do not show a significant increase in time. The regression analysis results of annual and summer temperatures are $\mathrm{F}=8.61, \mathrm{p}<0.001$, $\mathrm{R}^{2}=0.21, \mathrm{~F}=23.32, \mathrm{p}<0.0001$, and $\mathrm{R}^{2}=0.41$, respectively. There is a 0.38 and $0.32^{\circ} \mathrm{C}$ increase in average annual and summer temperatures, respectively. a)

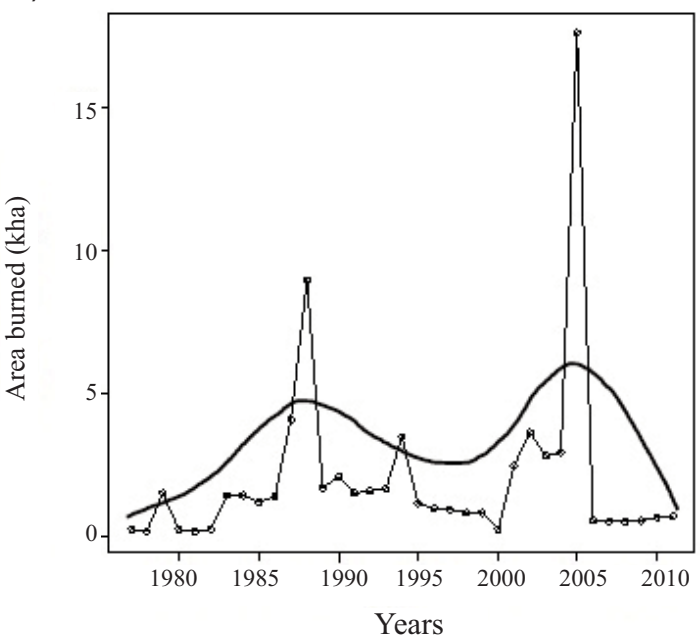

b)

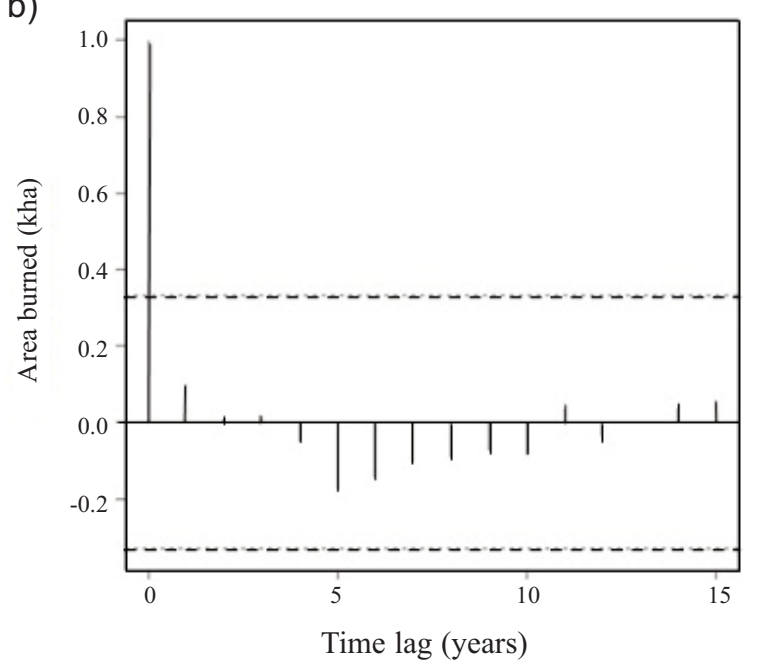

Fig. 4. The change in the amount of area burned in the Muğla region in the last 30 years. 
The correlation that was not found between annual area burned and annual precipitation was found in summer precipitation, even a little $(\mathrm{F}=4.2, \mathrm{p}=0.04)$. Although the mentioned correlation seems small, it is effective on the area burned, and there is an increase in the size of area burned in dry summers. Although the correlation between summer precipitation and number of fires seems small, the number of fires tends to decrease with increasing rainfall.

There is a positive cross-correlation between annual area burned and summer precipitation in a two-year period (lag of 2) (Fig. 6b). As a result, the linear regression between the area burned and summer precipitation is statistically significant at $\mathrm{F}=44.31, \mathrm{p}<0.001$.

\section{Discussion}

As in all other parts of the World, climate change significantly affects Europe, particularly the Mediterranean countries. Many studies have been carried out to date, and these studies reveal that the forests will be under the effect of difficult conditions due to climate change.
In a study on temperatures in the Mediterranean region, Hertig and Jacobeit [19] have stated that, when the entire Mediterranean region is considered (although still there is uncertainty in the distribution of the effects of climate change), significant temperature changes up to $40^{\circ} \mathrm{C}$ would be expected by the end of the century [19].

According to another study that Deque [20] carried out on France, it has been stated that the summer drought would increase, although the number of days with heavy rain during the winter would also increase. In addition, an increase is also expected in the number of days during which there will be heat waves [20]. Also, in their study on climate estimations for the future, Planton et al. [21] have stated that the most significant changes will be in temperature, and that the heat wave will be longer, stronger, and more frequent [21].

In their study, Goubanova and $\mathrm{Li}$ [22] analyzed the extreme temperature and precipitation changes in the Mediterranean region for two chosen future periods. It has been found that there is an increase in annual maximum and minimum temperatures in all regions. The highest increase in maximum temperatures has been found to be in southern a)

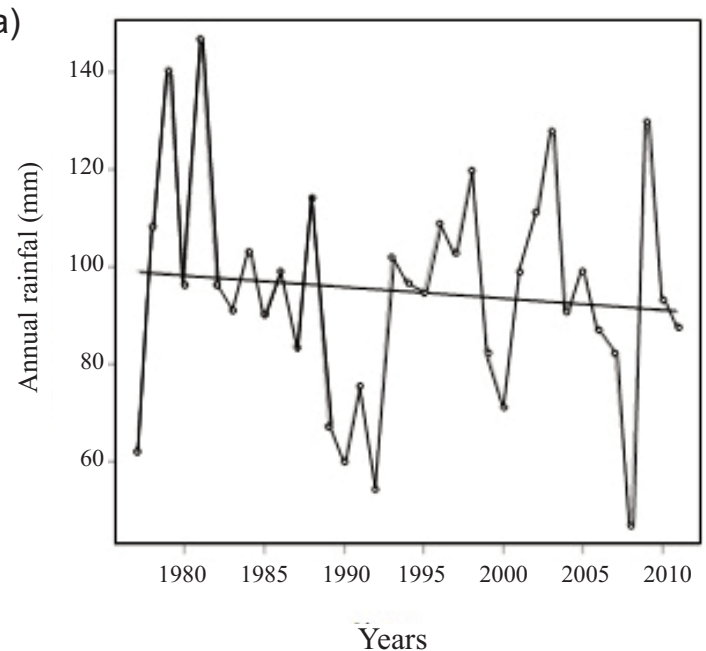

b)

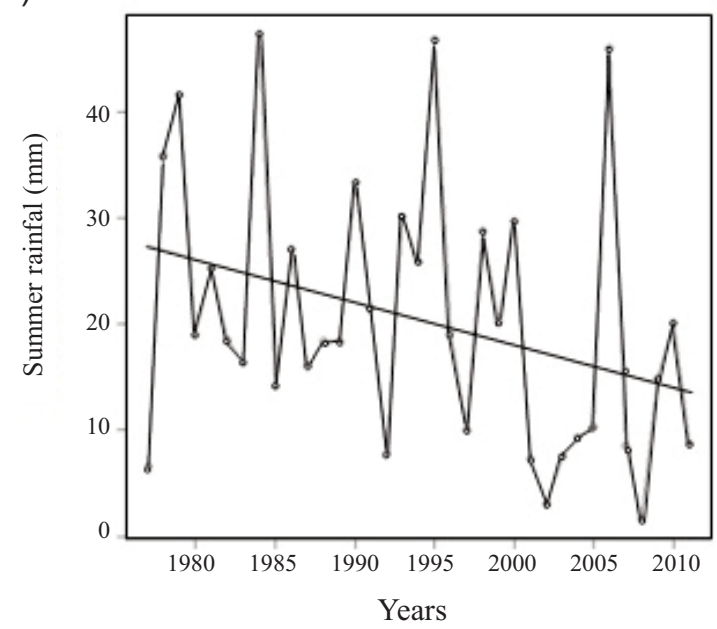

c)

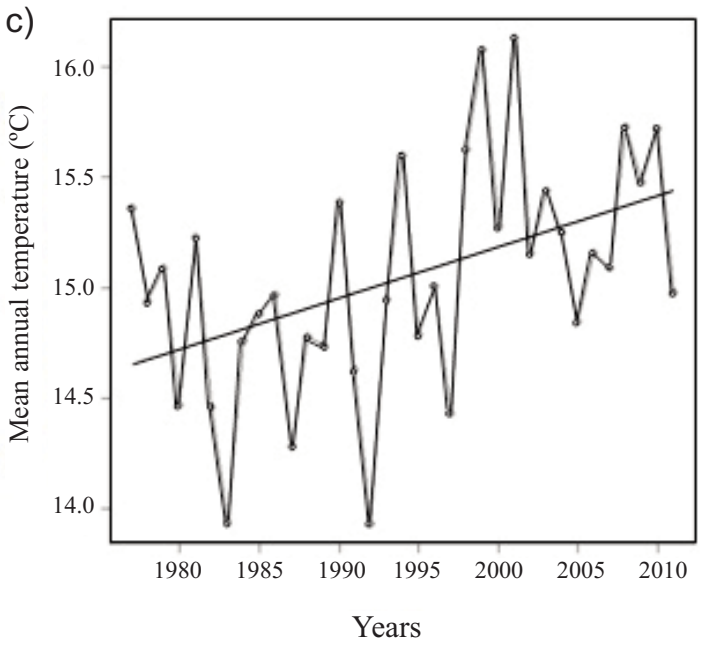

d)

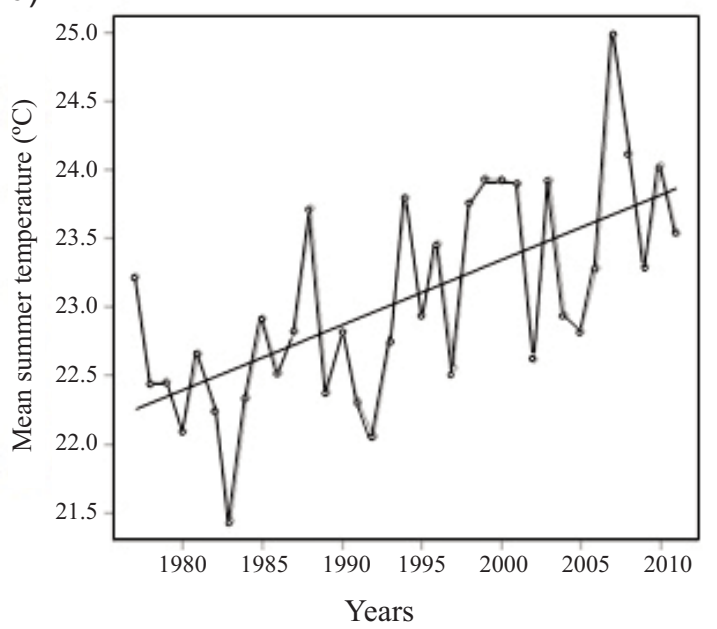

Fig. 5. The change in annual and summer precipitation in the last 30 years ( $a$ and $b$ ) and the average change in annual and summer precipitation (c and d). 
Europe. With regards to average precipitation, a decrease has been found for all seasons except autumn in southern Europe and the Mediterranean region [22].

The changing climate factors will have obvious impacts on forest fires. An increasing trend has been found in the area burned in Canada in the last 30 years. Again, in the same period, the fire season has become warmer. The results achieved have revealed that the increase in fire activity was related to climate change and carbon dioxide emissions [23]. Fire risk around the Mediterranean region increased with the extension of the fire season. Fire hazards will be a bigger threat in the Mediterranean region in the future. Since the precipitation does not increase, the increasing temperatures will cause drought in Mediterranean and Continental Europe's mild conditions. It is expected that the forest fire hazard in all Europe and particularly in the Mediterranean region will increase [24].

Morionda et al. [25], project that the fire hazard will increase not only in coastal Europe but also in the mountain forests in Mediterranean countries such as the Alpine region in Italy, the Pyrenees in Spain, and mountainous areas of the Balkans [25].

Whereas there is a significant positive correlation between years and number of fires in Turkey according to our study, there is a negative correlation between years and area burned. This means that the number of fires increases by years but the area burned in each fire decreases. We can correlate this situation with an increase in the number of human-induced and deliberately-induced fires, the increase in the population around forested areas, and with fires arising from energy lines and negligence.

Also, there is no correlation between the area burned and years.

The number of fires in Muğla, which ranks first in terms of fires and area burned, has increased in the last 30 years. The largest areas burned in fires in Muğla were 9,000 ha in 1988 and 17,000 ha in 2005. However, no correlation has been found between time and the amount of area burned in the field of study.
In the period of study, the annual temperatures and summer temperatures increased by $0.38^{\circ} \mathrm{C}$ and $0.32^{\circ} \mathrm{C}$. No correlation was found between annual area burned and annual precipitation. There is a small correlation between annual area burned and summer precipitation. However, this correlation, which is small in terms of numbers, has significantly affected the area burned in dry summer months recently. Although the correlation between summer precipitation and annual number of fires is small, the number of fires changes with the increase in precipitation.

Muğla has a strong pressure on forests due to its Mediterranean climate, tourism, high land value, increases in population, and intense migration. It has been seen that the coastal cities in the Mediterranean and Aegean in Turkey have started to receive high numbers of immigrants as of 1985 [26].

A study on increases in population-migration, which included Muğla, stated that there was a significant migration movement in five important cities in Turkey (Bursa, Mersin, Adana, Antalya, and Muğla) following the three largest metropolitan cities between 1985 and 1990, and the reasons for this high migration rate were industry and tourism [27].

High urbanization has negative impacts on forests. The urban population in Turkey increased by $347 \%$ between 1970 and 2004 [28].

Due to the increase in urban population, there has been a significant increase in $\mathrm{CO}_{2}$ emissions arising from energy, industry, agriculture, and waste (total $\mathrm{CO}_{2}$ emission increase 1990-2007 was 119.1\% [29].

It is now known that the reason of global climate change is man-made gases. These man-made gases triggered the greenhouse effect in the atmosphere, which ended 49 million years ago [30]. $\mathrm{CO}_{2}$, one of these gases, is the reason for the greenhouse effect in the atmosphere. According to Budzianowski [31], the $\mathrm{CO}_{2}$ gas in the atmosphere that causes global warming will peak before 2100 . It has been stated in the same study that the reason of the
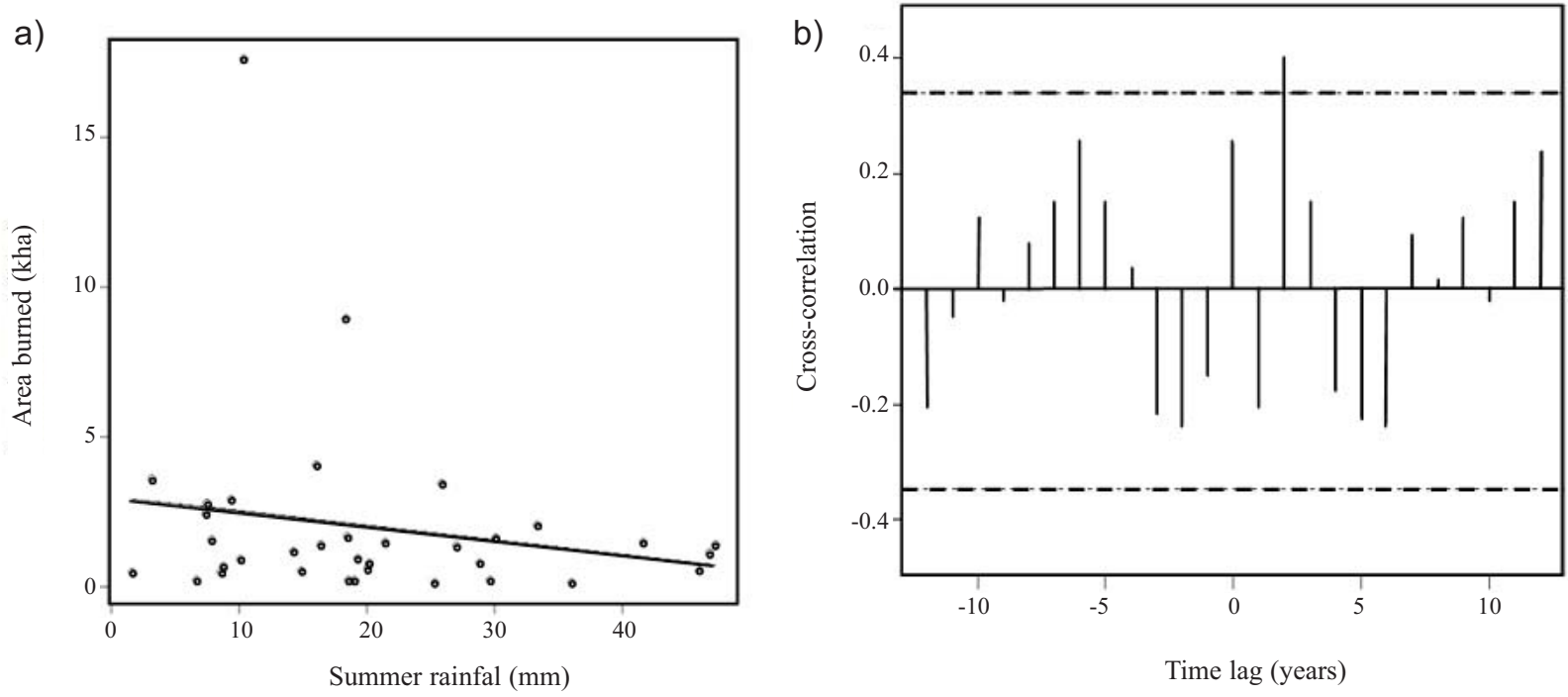

Fig. 6. The correlation between annual area burned and summer precipitation. 
given case is due to fossil fuel consumption continuing and the fact that the world population will peak in 2075 [31].

The field of this study is dry and hot during summers due to being in the Mediterranean climate zone. In addition, there has been an increase in temperatures and summer droughts due to recent global climate change. It has been known for many years that there is a direct correlation between the increase in temperatures and $\mathrm{CO}_{2}$ emissions. While $\mathrm{CO}_{2}$ emissions in the 1850 s were $270 \mathrm{ppm}$, this value reached up to $390 \mathrm{ppm}$ in 2010. In parallel, there had been a $10^{\circ} \mathrm{C}$ increase in temperatures in the same period [32].

Climate change, increase in population, migration, and tourism pressures has led to an increase in forest fire risk. As in all other Mediterranean countries, most of the large forest fires in Muğla are human-induced. Therefore, it is predicted that the forest fires in the Muğla region's forests may lead to wider problems under the effects of these factors, creating pressure on fires.

\section{References}

1. CHANDLER C., CHENEY P., THOMAS L., WILLIAMS D. Fire in Forestry, Forest Fire Behaviour and Effectes, John Wiley, New York, Vol. 1, pp. 450, 1983.

2. CLARK J.S. Fire and Climate Change During the Last 750 Year in Northwestern Minnessota. Ecol. Monogr. 60, 135, 1990.

3. EUROPEAN UNION-INTERACT. Focus Mediterranean Lab Group Forest fire risks analysis 2011. Thematic pole on natural risks with an inter-OPs perspective in the Mediterranean area. Lab group for a Mediterranean Platform - Capitalisation, 2011.

4. Retrived October 12, 2013, from http://data.giss.nasa.gov/gistemp/graphs_v3/, 2013.

5. FALK D.A., HEYERDAHL E.K., BROWN P.M., SWETNAM T.W., SUTHERLAND E.K., GEDALOF Z., YOCOM L., BROWN T.J. Fire and climate variation in western North America from fire-scar and tree-ring networks. PAGES news, 18, 2, 2010.

6. KOLDEN C.A., BROWN T.J. Beyond wildfire: perspectives of climate, managed fire and policy in the USA. Int. J. Wildland Fire, 19, 364, 2010.

7. OBREGON A., BISSOLLI P., KENNEDY J. J., PARKER D.E., SENSOY S. Mediterranean, Italian, and Balkan Peninsulas. State of the Climate in 2009. Special Supplement to the Bulletin of the American Meteorological Society, Vol. 91, No. 7, July 2010. Editors; D.S. Arndt, M.O. Baringer and M.R. Johnson, Associate Eds. L.V. Alexander, H.J. Diamond, R.L. Fogt, J.M. Levy, J. Richter-Menge, P.W. Thorne, L.A. Vincent, A.B. Watkins and K.M. Willett, 2009.

8. DALE V.H., JOYCE L.A., MCNULTY S., NEILSON R.P., AYRES M.P., FLANNIGAN M.D., HANSON P.J., IRLAND L.C., LUGO A.E., PETERSON C.J., SIMBERLOFF D., SWANSON F.J., STOCKS B.J., WOTTON B.M. Climate Change and Forest Disturbances. BioScience, 51, 9, 2010.

9. WOTTON B.M., MARTELL D.L., LOGAN K.A. Climate change and people-caused forest fire occurence in Ontario. Climatic Change 60, 275, 2003.

10. WOTTON B.M., LOGAN K., MCALPINE R. Climate Change and the Future Fire Environment in Ontario: Fire
Occurrence and Fire Management Impacts. Ontario Ministry of Natural Resources. Retrived November 22, 2013, from:

http://www.mnr.gov.on.ca/stdprodconsume/groups/lr/@ mnr/@climatechange/documents/document/276920.pdf, 2005.

11. LAURENTIAN FORESTRY CENTRE. Climate change and forest fires: the taiga is at risk. "Branching out" from the Canadian Forest Service. [Booklet], Number 50. Girardin, M.: Author, 2009.

12. ABATZOGLOU J.T., KOLDEN C.A. Relative importance of weather and climate on wildfire growth in interior Alaska. Int. J. Wildland Fire, 20, 479, 2011.

13. WESTERLING A.L. Climate and Wildfire in the Western United States. California Applications Program White Paper, Climate Research Division, Scripps Institution of Oceanography. NOAA Regional Integrated Science and Assesment Program. Retrieved September 18, 2013, from http://meteora.ucsd.edu/cap/pdffiles/westerling_fire08.pdf, 2008.

14. CARVALHO A. Climate change, forest fires and air quality in Portugal in the $21^{\text {st }}$ century. Climate Change and Variability. Edited by Suzanne Simard, ISBN 978-953-307144-2. DOI: 10.5772/1743, 2010.

15. ZUMBRUNNEN T., BUGMANN H., CONEDERA M., BURGI M. Linking Forest Fire Regimes and Climate - A Historical Analysis in a Dry Inner Alpine Valley. Ecosystems, 12, 73, 2009. DOI: 10.1007/s10021-008-9207-3

16. PAUSAS J.G. Changes in fire and climate in the eastern iberian peninsula (Mediterranean Basin). Climatic Change. 63, 337, 2004.

17. PINOL J., TERRADAS J., LLORET F. Climate warming, wildfire hazard, and wildfire occurrence in coastal Eastern Spain. Climatic Change. 38, 345, 1998.

18. VENABLES W.N., RIPLEY B.D. Modern Applied Statistics with S-Plus, $3^{\text {rd }}$ edn., Springer, pp. 501, 1999.

19. HERTIG E., JACOBEIT J. Assessments of Mediterranean precipitation changes for the $21^{\text {st }}$ century using statistical downscaling techniques. I. J. Climatol., 28, (8), 1025, 2008.

20. DEQUE M. Frequency of precipitation and temperature extremes over France in an anthropogenic scenario: Model results and statistical correction according to observed values. Global Planet. Change, 57, 16, 2007.

21. PLANTON S., DÉQUÉ M., CHAUVIN F., TERRAY L. External geophysics, climate and environment, Expected impacts of climate change on extreme climate events. C. R. Geoscience, 340, 564, 2008.

22. GOUBANOVA K., LI L. Extremes in temperature and precipitation around the Mediterranean basin in an ensemble of future climate scenario simulations. Global Planet. Change, 57, (1-2), 27, 2007.

23. GILLETT N.P., WEAVER A.J., ZWIERS F.W., FLANNIGAN M.D. Detecting the effect of climate change on Canadian forest fires. Geophys. Res. Lett. 31, L18211, 2004. doi:10.1029/2004GL020876

24. Retrived November 21, 2013, from http://ec.europa.eu/agriculture/analysis/external/euro_forests/summary_en.pdf, 2013.

25. MORIONDO M., GOOD P., DURAO R., BINDI M., GIANNAKOPOULOS C., CORTE-REAL J. Potential impact of climate change on fire risk in the Mediterranean area. Climate Res. 31, 85, 2006.

26. GÜMÜŞ E. Türkiye'nin nüfusu, from: http://w2.anadolu.edu.tr/aos/kitap/IOLTP/2291/unite06.pdf, 2014. 
27. GEZICI F., KESKIN B. Interaction between Regional Inequalities and Internal Migration in Turkey, from http://www.ekf.vsb.cz/export/sites/ekf/projekty/cs/weby/esf -0116/databaze-prispevku/clanky_ERSA 2005/132.pdf, 2005.

28. ATMIŞ E., ÖZDEN S. Urbanization pressures on the natural forests in Turkey: An overview. Urban Forestry \& Urban Greening, 6, 83, 2007.

29. http://www.lrqa.com.tr/Images/turkiye\%20sektorel_tcm 143-192601.jpg, 2014.
30. BUDZIANOWSKI W. M. Tetra-stable bifurcation structure of the climate system of Earth: mechanisms triggering potential transition to the greenhouse steady state. International Journal of Global Warming, 5, (2), 152, 2013.

31. BUDZIANOWSKI W. M. Modelling of $\mathrm{CO}_{2}$ content in the atmosphere until 2300: Influence of energy intensity of gross domestic product and carbon intensity of energy, International Journal of Global Warming, 5, (1), 1, 2013.

32. http://www.globalccsinstitute.com/publications/globalstatus-ccs-2011/online/26861 2011. 
